\title{
Natural resources to control COVID-19: Could lactoferrin amend SARS-CoV-2 infectivity?
}

\author{
Ehab Mattar ${ }^{1}$, Fatma Elrashdy ${ }^{2}$, Hussein Almehdar ${ }^{1}$, Vladimir N Uversky ${ }^{\text {Corresp., } 3}$, Elrashdy Redwan ${ }^{\text {Corresp. } 1}$ \\ ${ }^{1}$ Biological Science Department, Faculty of Science, King Abdulaziz University, Jeddah, Saudi Arabia \\ 2 Department of Endemic Medicine and Hepatogastroenterology, Cairo University, Cairo, Egypt \\ 3 Department of Molecular Medicine, University of South Florida, Tampa, Florida, United States \\ Corresponding Authors: Vladimir N Uversky, Elrashdy Redwan \\ Email address: vuversky@usf.edu, Iradwan@kau.edu.sa
}

The world population is still facing the second wave of the COVID-19 pandemic. Such a challenge requires complicated tools to control, namely vaccines, effective cures, and complementary agents. Here we present one candidate for the role of an effective cure and/or complementary agent: lactoferrin. It is the cross-talking mediator between many organs/cellular systems in the body. It serves as a physiological, immunological, and antimicrobial barrier, and acts as a regulator molecule. Furthermore, lactoferrin has receptors on most tissues cells, and is a rich source for bioactive peptides, particularly in the digestive system. In the past months, in vitro and in vivo evidence has accumulated regarding lactoferrin's ability to control SARS-CoV-2 infectivity in different indicated scenarios. Also, lactoferrin or whey milk (of human or other mammal's origin) is a cheap, easily available, and safe agent, the use of which can produce promising results. Pharmaceutical and/or food supplementary formulas of lactoferrin could be particularly effective in controlling the gastrointestinal COVID-19-associated symptoms and could limit the fecal-oral viral infection transmission, through mechanisms that mimic that of norovirus infection control by lactoferrin via induction of intestinal innate immunity. This natural avenue may be effective not only in symptomatic patients, but could also be more helpful in asymptomatic patients as a main or adjuvant treatment. 
1 Natural resources to control COVID-19: Could

2 lactoferrin amend SARS-CoV-2 infectivity?

3

4

5

6

7

8

9

10

11

12

13

14

15

16

17

18

19

20

21

22

23

24

25

26

27

28

29

30

31

32

33

34

35

36

37

38

39

40

\section{Ehab Mattar ${ }^{1}$, Fatma Elrashdy ${ }^{2}$, Hussein A. Almehdar ${ }^{1}$, Vladimir N. Uversky ${ }^{1,3, *}$, and} Elrashdy M. Redwan ${ }^{1, *}$

1 Biological Science Department, Faculty of Science, King Abdulaziz University, P.O. Box 80203, Jeddah, 21589, Saudi Arabia; emattar@kau.edu.sa (E.M.); dralmehdar@hotmail.com (H.AA.); 1radwan@kau.edu.sa (E.M.R.)

2 Department of Endemic Medicine and Hepatogastroenterology, Kasr Alainy School of Medicine, Cairo University, Cairo, Egypt; Fatmaelrashdy@kasralainy.edu.eg (F.A.)

3 Department of Molecular Medicine and USF Health Byrd Alzheimer's Research Institute, Morsani College of Medicine, University of South Florida, Tampa, FL, USA; vuversky@usf.edu

Corresponding Authors:

Vladimir N. Uversky

Department of Molecular Medicine and USF Health Byrd Alzheimer's Research Institute, Morsani College of Medicine, University of South Florida, Tampa, FL, USA

Email address: vuversky@usf.edu

Elrashdy M. Redwan

Biological Science Department, Faculty of Science, King Abdulaziz University, P.O. Box 80203, Jeddah, 21589, Saudi Arabia

Email address: $\underline{\text { lradwan@kau.edu.sa }}$

\section{Abstract}

The world population is still facing the second wave of the COVID-19 pandemic. Such a challenge requires complicated tools to control, namely vaccines, effective cures, and complementary agents. Here we present one candidate for the role of an effective cure and/or complementary agent: lactoferrin. It is the cross-talking mediator between many organs/cellular systems in the body. It serves as a physiological, immunological, and anti-microbial barrier, and acts as a regulator molecule. Furthermore, lactoferrin has receptors on most tissues cells, and is a rich source for bioactive peptides, particularly in the digestive system. In the past months, in vitro and in vivo evidence has accumulated regarding lactoferrin's ability to control SARS-CoV-2 infectivity in different indicated scenarios. Also, lactoferrin or whey milk (of human or other mammal's origin) is a cheap, easily available, and safe agent, the use of which can produce promising results. Pharmaceutical and/or food supplementary formulas of lactoferrin could be particularly effective in controlling the gastrointestinal COVID-19-associated symptoms and could limit the fecal-oral viral infection transmission, through mechanisms that mimic that of norovirus infection control by lactoferrin via induction of intestinal innate immunity. This natural avenue may be effective not 
only in symptomatic patients, but could also be more helpful in asymptomatic patients as a main or adjuvant treatment.

\section{Introduction}

The year 2020 will be recorded in human history as the year of the COVID-19 pandemic, which infected and killed millions of people. The virus reached almost all countries, infected humans of all ages, and even affected many animals (Uversky et al. 2020b). The virus reaches almost all human organs, including the central and peripheral nervous systems (Elrashdy et al. 2020c; Uversky et al. 2020a), and has unexpected vertical and horizontal infectivity potential (Elrashdy et al. 2020a; Elrashdy et al. 2020b). The scientific community is still facing a major challenge to discover a preventive vaccine or standard therapeutic agent(s) for this virus.

In addition to immunoglobulins, the multifunctional protein lactoferrin (LF) is being considered as one of the mucosal surface defense molecules. It is a globular glycoprotein with $80-\mathrm{kDa}$, consisting of $\mathrm{N}$ - and $\mathrm{C}$-terminal lobes. While the $\mathrm{C}$-lobe contains more $\mathrm{N}$-linked glycosylation sites, both parts of the LF are glycosylated. Each lobe of LF is able to bind a ferric ion concomitantly with a bicarbonate anion. However, being a metalloprotein, LF can bind other metals (e.g., zinc and manganese) in its two binding sites. LF is secreted by the exocrine glands and neutrophils and is present in most human secretions, such as tears, milk, vaginal mucus, seminal plasma, and saliva (Conesa et al. 2008; El-Agamy 2006; El-Fakharany et al. 2012; Legrand et al. 2008; Liao et al. 2012; Lonnerdal 2009). LF milk content fluctuates between mammalian species and, within a single species, depends on the lactation period.

LF is known to have many functions, ranging from immunoprotective to physiological ones, such as iron sequestration, where its main role is controlling free iron levels in external secretions and blood. It also interacts with lipopolysaccharides (LPS), peptidoglycan, ribonucleic acids, polysaccharides, and heparin, and displays pronounced antiviral and antimicrobial activity. This plethora of functions can be attributed to the fact that, structurally, LF is a hybrid protein that possesses ordered domains as well as functionally significant intrinsically disordered regions (Berlutti et al. 2011; Oda et al. 2020; Ostan et al. 2021). LF and its lobes display noteworthy antimicrobial and antiviral activities against many infectants, including Gram-negative and Grampositive bacteria and both enveloped and non-enveloped viruses, with these antimicrobial and antiviral potentials being dependent on the type of microbes and viruses (Albar et al. 2014; Redwan et al. 2014b). It is believed that most of the antimicrobial activities can be ascribed to the N-lobe. In addition, LF and its two lobes display significant anti-inflammatory, wound healing, anticancer, and immunomodulation activities. As an antiviral, LF acts primarily at the acute phase of infection, or even at the intracellular stage (e.g. during a hepatitis $\mathrm{C}$ infection) (El-Fakharany et al. 2013; Liao et al. 2012; Redwan el \& Tabll 2007; Redwan et al. 2014a). LF impedes viral entry into the host cell in one of two ways: either by blocking the viral particles' corresponding cellular receptors, or by direct attachment to their proteins (Redwan et al. 2014b). 
80 Lactoferrin's wide variety of functions could be attributed to its capacity for iron sequestration 81 and/or the ability to interfere with the cellular receptors of both pathogenic microbes and their 82 hosts (Albar et al. 2014; Redwan et al. 2014b). In this work, we discuss the potential of LF to 83 combat COVID-19 by examining recent in vivo and in vitro experimental research. Two review 84 articles were recently published concerning the potential effect of LF against SARS-CoV-2 (Chang 85 et al. 2020; Wang et al. 2020). Although both of these reviews used previously published data on 86 the effects of LF against SARS-CoV and other viruses, they did not consider the results of the 87 88 89 90 91 more recent research focused on SARS-CoV-2. Furthermore, these previous articles (Chang et al. 2020; Wang et al. 2020) did not cover many interesting in vitro and/or in vivo experimental reports, which generated a wealth of important data on the molecular mechanisms of LF action against SARS-CoV-2, on comparison of the human and animal LFs, and on determining whether the milk whey action against SARS-CoV-2 depends on LF alone or on other milk ingredients, such as human milk oligosaccharides (HMOs) and/or short-chain fatty acids. Our report fills these gaps and produces an overview of the field, providing answers to some fundamental questions, such as why breastfed children are mostly unaffected by COVID-19 (Fan et al. 2020; Liu et al. 2021; Mitoulas et al. 2020). In addition, we enumerate the effects and the scenarios (based on viral and host factors) of how LF would work against SARS-CoV-2. Although the results of the potential LF use against COVID-19 are promising, a few limitations were recognized as well, such as the prominent anticoagulant effects of this protein and the peptides derived from it (Shute et al. 2018), which have also never been mentioned before. We hope that this report will expand the audience and will be of interest to readers with different backgrounds, from physicians to researchers working on biomedical and biological projects.

102

\section{Survey methodology}

104

For data collection, we conducted an electronic search to identify a set of comprehensive studies containing eligible data. To this end, Medline database through PubMed and Scopus, WEB of Knowledge, and Collabovid databases were searched to obtain related articles published from December 2019 up to January 15, 2021. The articles were scanned based on their titles and abstracts. The subject terms used in the search were human lactoferrin, bovine lactoferrin, animal lactoferrin, in vitro effects, in vivo. Each of these individual keywords alone or in different combinations were further pooled with "COVID-19" and/or "SARS-CoV-2" and/or "coronaviruses". Then the retrieved data were classified according to the different categories, such as review articles, research articles (published in peer-review journals or posted preprints), and clinical trials.

114

\section{Results of literature search}

116 Through this literature search, more than 100 studies were identified that were directly or indirectly related to the description of the interplay between LF and COVID-19 and LF-SARS-CoV-2 interactions. We selected articles that were most related to COVID-19, with priority being given 
120 SARS-CoV-2 interactions that were not covered in previous reviews. Most of the experimental

121

122

123

124

125

126

127

128

129

130

131

132

133

134

135

136

137

138

139

140

141

142

143

144

145

146

147

148

149

150

151

152

153

154

155

156

157

reports were dedicated to the in vitro evaluation of the potentials of the full-length LF of human or animal origin against coronaviruses (virulent or pseudovirus) using many cell lines culture systems. Only two reports were dedicated to the evaluation of the effects of formulated LF on COVID-19 patients, and a single study described the results of the analysis of the whey milk antiviral activity.

\section{Dual lactoferrin functions}

LF is a multifunctional protein utilizing at least 8 types of receptors, such as a) lactoferrin receptor/LRP-1/CD91/apoE receptor or the chylomicron remnant receptor, b) intelectin-1 (omentin-1), c) TLR2, d) TLR4, e) CXCR4, f) CD14, g) Heparan sulfate proteoglycans (HSPGs), and $\mathrm{h}$ ) interleukin-1 distributed in almost all cells of the human body, as reviewed in (Kell et al. 2020). These different kinds of receptors enable LF to perform its various physiological and immunological functions.

It is known that LFs of different origin may show differences in their antiviral and antibacterial activities. For example, camel LF (cLF) showed higher inhibitory effects on the hepatitis $\mathrm{C}$ virus (HCV, genotype 4a) than human, bovine, and sheep LFs (hLF, bLF, and sLF, respectively). It is also likely that cLF might show significant anti-SARS-CoV-2 activity. There are at least three characteristics that make cLF unique among the LFs from other species (El-Fakharany et al. 2013): 1) the glycosylation pattern of cLF is different from those of other LFs; 2) some residues in cLF, such as $\mathrm{PrO}_{418}$, $\mathrm{Leu}_{423}, \mathrm{Lys}_{433}$, Pro ${ }_{592}, \mathrm{Gly}_{629}, \mathrm{Lys}_{637}, \mathrm{Gln}_{651}$, and $\mathrm{Arg}_{652}$ that are critical for domain movement are different from those in LFs from other species, suggesting the existence of specific differences related to structural dynamics of cLF; 3) the $\mathrm{N}$ - and C-lobes of cLF are characterized by different iron release mechanisms, losing their iron at acidic $\mathrm{pH}$ (below $\mathrm{pH} 4.0$ ) and neutral $\mathrm{pH}$ 6.5, respectively. Therefore, unlike other LFs and transferrins, cLF acts as both an iron-binding protein (LF) and an iron transporter protein (transferrin) (Khan et al. 2001), since it loses about half of its iron content at neutral $\mathrm{pH}$, and the other half is lost at acidic conditions ( $\mathrm{pH}$ 4.0-2.0). Curiously, it was shown that the lipid peroxidation can be inhibited by treatment with bovine LF (bLF) (El-Fakharany et al. 2017; Konishi et al. 2006), whereas cLF may show a dual-action, inhibiting lipid peroxidation and regulating the hepatic-iron content due to being able to bind and transport iron at a wide $\mathrm{pH}$ range (acidic to basic) (Khan et al. 2001).

\section{A direct effect of lactoferrin on viral particles}

As previously established (Albar et al. 2014; Liao et al. 2012; Redwan et al. 2014b), most of the LF forms (natural, recombinant, full length, N-lobe, or C-lobe) exert their antiviral activity through three standard strategies (Figure 1):

\section{Targeted cell protection}




\section{Targeted treatment of the infected cell (intracellular viral inhibition)}

\section{Viral neutralization (extracellular inhibition)}

In vitro evaluation of the activity of (bovine/human) LF against the virulent SARS-CoV-2 using several cell-lines (Vero E6, Caco-2, adenocarcinoma human alveolar basal epithelial cells, A549, Huh7, HEK293T cell expressing ACE2 (293T-ACE2), HCT-8, Calu-3, and MRC-5 cell lines) clearly showed that LF is capable of inhibition of viral activity, in a dose-dependent manner, via the three aforementioned strategies (Campione et al. 2020b; de Carvalho et al. 2020; Fan et al. 2020; Mirabelli et al. 2020). In addition to these observations, another study emphasized that the anti-SARS-CoV-2 activity is not limited to LF alone, but can be expanded to other components found in total whey milk (Fan et al. 2020). Whey milk could be even more effective in blocking/neutralizing the viral attachment, entry, and post-entry replication. This study showed that whey protein from an animal (goat and cow) inhibited the infectivity of both the SARS-CoV-2 pseudovirus and the related GX_P2V virus, though the degree of inhibition was lower than that of human whey protein (Fan et al. 2020). These findings suggest that human whey protein contains higher concentrations of antiviral components and/or antiviral components with higher potency than those found in other species.

Although Fan et al. (2020) excluded the possibility that the anti-SARS-CoV-2 activity was due to the whey milk IgA, since the human milk was collected before the emergence of SARS-CoV-2 (Fan et al. 2020), one could not exclude the possibility of milk fermentation during this time, which subsequently created various types of small $(\leq 3 \mathrm{kDa})$ bioactive peptides (Madadlou 2020). Furthermore, free fatty acids generated by milk lipases (such as lipoprotein lipase and the bile saltstimulate lipase) could destroy many RNA-enveloped viruses of di $\square$ erent families (Conzelmann et al. 2019). Antimicrobial, anti-ACE, anti-hypotension, and anti-hypertensive inhibitor bioactive peptides were created not only from human milk but were also obtained from sheep, bovine, goat, buffalo, and camel milk (Abd El-Salam \& El-Shibiny 2012; Dave et al. 2016; Rahimi et al. 2016; Rai et al. 2017; Wada \& Lönnerdal 2020; Yahya et al. 2017). However, IgA antibodies from recovered patients were shown to be able to block the interaction of ACE2 and SARS-CoV-2 (Ejemel et al. 2020). This conclusion was supported by Wettstein et al. (2020) who provided evidence that alpha-1 antitrypsin ( $\alpha 1-\mathrm{AT}$ ) inhibits SARS-CoV-2 (virulent isolate and pseudoparticles) infection through targeting the viral spike protein and then blocks the SARSCoV-2 infection of human airway epithelium at physiological concentrations (Wettstein et al. 2020).

In addition to human whey milk proteins, peptides, glycopeptides, and short-chain fatty acids (SCFAs), there are hundreds of bioactive structures of human milk oligosaccharides (HMOs), which are the third most abundant solid components of whey milk, after lactose and lipid. In fact, about 5-15 g/L of HMOs are present in human milk (He et al. 2016; Ramani et al. 2018; Triantis et al. 2018). As a result, HMOs are known to play fundamental roles in infant and adult bodies through three major functions related to innate immunity: 1) inhibition of binding of various pathogens to their corresponding receptors due to their structural homology with the host-mucosal cell surface receptors; 2) prebiotic activity and shaping the intestinal microbiota; 3) 
198

199

200

201

202

203

204

205

206

207

208

209

210

211

212

213

214

215

216

217

218

219

220

221

222

223

224

225

226

227

228

229

230

231

232

233

234

235

236

237

immunoregulation and modulation of inflammation. This unique structural repertoire of HMOs is restricted to human milk, and is very limited or entirely missing in bovine milk (Ramani et al. 2018), which may explain why human whey milk was more effective against the SARS-CoV-2 and GX_P2V viruses (Fan et al. 2020). These results may have a fundamental answer for the question of why COVID-19 morbidity and mortality in children and infants are very limited. LF was also shown to be capable of inhibiting infection of human cells by the SARS pseudovirus (Lang et al. 2011), and its production is up-regulated during the coronavirus infection about 150fold (Reghunathan et al. 2005). In the rat model, the ingestion of exogenous LF enhanced protection against sepsis-induced acute lung injury (ALI) (Han et al. 2020; Han et al. 2019). It is also possible that the exogenous intake of LF by ingestion of milk products might enhance protection against SARS-CoV-2 infection, as shown in recent published results, which indicated the inhibitory roles of food/milk ingredients against cellular SARS-CoV-2 entry (Fan et al. 2020; Hoffmann et al. 2020; Madadlou 2020; Ou et al. 2020; Sano et al. 2005). However, it should be noted that PF-4, LF, IL-8 (CXCL8), and polyarginine neutralize the anticoagulant activity of heparin (Shute et al. 2018), particularly in COVID-19 patients associated with thrombocytopenia and LF and IL-8 upregulation. Respiratory secretions contain high LF concentrations (0.1$1.0 \mathrm{mg} / \mathrm{ml}$ ), where it completely neutralizes the heparin anticoagulation effects at $10 \mu \mathrm{g} / \mathrm{ml}$ (Shute et al. 2018). Also, LF could exert antithrombotic activity through its ability to regulate the plasminogen activation and coagulation cascade control (Kell et al. 2020; Zwirzitz et al. 2018). This antithrombotic activity is not limited to lactoferrin, but is extended and confirmed by the ability peptide sequence derived from it (Xu et al. 2020b).

Recently published experimental data revealed that both the holo- and apo-forms of LF (holo-LF and apo-LF) can effectively inhibit entry and replication of SARS-CoV-2, thereby acting as effective inhibitors of SARS-CoV-2 infection with an $\mathrm{IC}_{50}$ of $308 \mathrm{nM}$, and these protein forms were capable of potentiation of the efficacy of both remdesivir and hydroxychloroquine (Mirabelli et al. 2020). Furthermore, Hu et al., 2021 reported that bLF has synergistic antiviral effect with remdesivir on coronaviruses (Hu et al. 2021). The evidence for the existence of such synergism supported the translational potential of LFs as broad-spectrum antivirals that can be used against coronaviruses, including SARS-CoV-2. Although both human and bovine LFs possessed the dosedependent capability to inhibit viral entry into all analyzed cell types, bovine LF showed a significantly higher reactivity than human $\mathrm{LF}$, with corresponding $\mathrm{IC}_{50}$ values of 44.9 and $466 \mathrm{nM}$, respectively ( $\mathrm{Hu}$ et al. 2021; Mirabelli et al. 2020). Although bLF was more effective than hLF, $\mathrm{Hu}$ et al. 2021, in an in vitro comparison study that utilized many cell-line systems and a battery of LF concentrations revealed that both human and bovine LFs have a wide spectrum of inhibitory activity against many types of human coronaviruses (HCoV-229E, HCoV-NL63, and HCoVOC43), which agrees with the results of the antiviral activities assay of bLF/hLF against a pseudovirus of SARS-CoV-2 in all cell-lines tested. These results clearly indicate that the inhibition of SARS-CoV-2 pseudovirus entry by LFs is cell type independent (Hu et al. 2021). Therefore, it seems that the molecular mechanisms behind the LF inhibitory effects can be attributed to the blockage of heparan sulfate proteoglycans (HSPGs) by LF (Hu et al. 2021).

Peer) reviewing PDF | (2021:01:57322:1:0:NEW 13 Mar 2021) 
238 Therefore, screens generated important results demonstrating that LF acts as an efficient SARS$239 \mathrm{CoV}-2$ inhibitor in vitro with multimodal efficacy. In addition, LF was able to retain its anti-SARS$240 \mathrm{CoV}-2$ activity 24 hours post-infection, suggesting the presence of some additional mechanisms 241 of action other than simple entry inhibition (Mirabelli et al. 2020). In fact, during Huh 7 cell 242 treatment with LF, up-regulation of the expression of several interferon-stimulated genes ( $M X I$, 243 ISG15, IFITM3, and RSAD2 that encodes radical S-adenosyl methionine domain-containing 244 protein 2 also known as Viperin) was observed (Mirabelli et al. 2020). Similarly, although the 245 addition of LF $(100 \mu \mathrm{g} / \mathrm{mL})$ induced a partial inhibition of SARS-CoV-2 multiplication in pre246 infected Caco-2 intestinal epithelial cells, this protein significantly induced and upregulated the 247 expression of many innate and adaptive immunity markers, such as IFNA1, IFNB1, TLR3, TLR7, 248 IRF3, IRF7 and MAVS (Salaris et al. 2021). Based on this in vitro potential of bLF against SARS$249 \mathrm{CoV}-2$, the authors suggested that LF combined with Vitamin D will be valid adjuvant therapeutic 250 tool for patients with COVID-19 (Salaris et al. 2021).

251 LF also stimulated an antiviral host cell response and maintained inhibitory activity in alveolar 252 epithelial cells derived from induced pluripotent stem cells (iPSC), which act as a model for the 253 254 primary site of infection. Since LF has not been shown to have adverse effects in humans, these findings suggest that this protein can be considered as a readily translatable adjunctive therapy for COVID-19 (Costagliola et al. 2021; Mirabelli et al. 2020). Furthermore, the fermentation of milk and/or LF by gut microbiota releases many active compounds (Cockburn \& Koropatkin 2016) that may directly interact with the viral particles and/or modulate the immune response. In a recent study (Figueroa-Lozano et al. 2020), scanned the effects of N-glycans derived from bovine LF on 259 monocyte-derived dendritic cells. This study revealed that although TLR-2, TLR-5, TLR-7, and TLR-9 were not significantly altered, the different isolated N-glycan forms from bLF possessed a 261

262 tight regulation of TLR-3, TLR-4, and TLR-8, as well as increased the IL-6 production (FigueroaLozano et al. 2018).

263 Of note, TLR-8 senses the viral ssRNA rich in adenylate and uridyalte, with this recognition 264

265

266

267 leading to the activation of the innate immune response (Tanji et al. 2015). Figure 2 represents a general scenario of the creation of small metabolites via digestion of the glycosylated LF and/or other whey milk glycoproteins by different microorganisms found in the intestinal microbiota and 268 the effects of these compounds on COVID-19 (Cockburn \& Koropatkin 2016; Karl 2021; Ren et 269 al. 2021). The important roles of different type of microbiota (specifically the intestinal 270 microorganisms) in COVID-19 development, severity, and/or recovery have been attracting the

271 increased interest of researchers (Costagliola et al. 2021; Karl 2021). Currently (as of February 27, 272 COVID-19 patients (clincaltrail.gov). 2021), there are at least 32 enrolled clinical trials using microbiota (of different source or form) in

273 Based on the net charge, bLF has been shown to prevent viral entry into host cells utilizing 274 competitive binding to the cell surface receptors, primarily the negatively charged compounds 275 such as glycosaminoglycans (GAGs) (Berlutti et al. 2011; Wakabayashi et al. 2014). However, 276 cLF is more competitive in this respect due to its highly anionic nature (El-Fakharany et al. 2013; 277 Redwan et al. 2014a). In addition, LFs are able to inhibit viral infections by binding to DC-SIGN 
278 and LDL receptors (Chien et al. 2008; Groot et al. 2005). Using anti-TMPRSS2 inhibitors leads to 279 incomplete inhibition of SARS-CoV-2 entry, while complete inhibition was reached by using both 280 anti-TMPRSS2 as well as cathepsin L/B inhibitors (Hoffmann et al. 2020; Ou et al. 2020). It is 281 worth noting that many food bioactive peptides and proteins could inhibit SARS-CoV-2 282 (Madadlou 2020). Lactoferrin is one of these bioactive inhibitors for SARS-CoV-2, through 283 inhibition of cathepsin L only at an elevated affinity $\left(\sim 10^{-7}\right)$ (Sano et al. 2005). Overall, LF shows

284

285

286

287

288

289

290

291

292

293

294

295

296

297

298

299

300

301

302

303

304

305

306

307

308

309

310

311

312

313

314

315

316

317

its antiviral e $\square$ ects at the early phase of infection, stopping viral particles from entering the host cells by either binding to the viral particles directly or by blocking cellular receptors. LF exerts its antiviral activity through direct interaction with the surface components of the viral particles (Berlutti et al. 2011; Oda et al. 2020). For example, LF was shown to bind to the E1 and E2 proteins of HCV (Yi et al. 1997), to the F protein of respiratory syncytial virus (RSV) (Sano et al. 2003), and to the gp120 protein of HIV (Puddu et al. 1998). Furthermore, when exerting its antiviral activity against Echovirus 6, LF interacts with both host cells and viral particles, (Tinari et al. 2005). As LF is one of the mucosal membrane defense proteins, in addition to its potential of host cell receptor binding it can strongly bind viral particle glycoproteins to inhibits viral entry (Valenti \& Antonini 2005). Lang et al. explored the role LF plays in the entry of the SARS pseudovirus into Myc cells and showed that it could block the binding of the viral spike protein to host cells, suggesting that LF performed its inhibitory function for SARS at the viral attachment stage (Lang et al. 2011).

The currently accepted model (Figure 3) suggests that LF can prevent infection of the target cells by SARS-CoV-2 by interfering with the attachment factor, or by binding to host cell molecules that the virus uses as a receptor (ACE2) or co-receptors (competition) such as HS-PG and Sialoside glycosaminoglycans (SIA-PG), or by direct binding to virus particles, as described for herpesvirus, polio, rotavirus, and R5 and X4-HIV-1, and/or via the intracellular localization involving inflammatory pathways or apoptosis (Berlutti et al. 2011; Saidi et al. 2006). If all these models were harnessed together, LF's anti-SARS-CoV-2 capacities would be considerably higher. In a recent analysis of the potential molecular mechanisms by which LF can interfere with SARS-CoV2 cell invasion (Miotto et al. 2020) it was shown that several regions on the LF surface are capable of binding to the sialic acid receptors on the host cell membrane, thereby shielding the cell from virus attachment. Furthermore, although there is no significant shape complementarity between LF and ACE2, LF contains regions of high complementarity with the $\mathrm{N}$ - and $\mathrm{C}$-terminal domains of the SARS-CoV-2 spike protein, with the most complementary region being the one in the Cterminal region, which is involved in the spike-ACE2 interaction (Miotto et al. 2020).

Therefore, the observed antiviral action of LF can be, at least in part, attributed to an efficient competition between ACE2 and LF for binding to the SARS-CoV-2 spike protein (Burckhardt \& Greber 2009; Llorente García \& Marsh 2020; Miotto et al. 2020). In light of its ability to enter the cell and pursue the nucleus, LF may also have abolished the cytokine storm cascade activation, therefore avoiding systemic complications as well as disease exacerbation.

Importantly, LF is also capable of exerting its antiviral activity when it is added at the postinfection phase, as demonstrated in HCV infection (El-Fakharany et al. 2013; Liao et al. 2012;

Peer) reviewing PDF | (2021:01:57322:1:0:NEW 13 Mar 2021) 
318 Redwan et al. 2014a), in HIV infection by Puddu et al. (Puddu et al. 1998), and in Rotavirus 319 infection by Superti et al. (Superti et al. 1997). LF's e $\square$ cacy during the post-infection phase 320 suggested that it can also be useful for impacting multiple intracellular steps of virus infection 321 (Kell et al. 2020).

\section{Host immune system modulation action of lactoferrin}

323 The immunomodulatory action is an important functional feature of LF, which can not only

324

325

326

327

328

329

330

331

332

333

334

335

336

337

338

339

340

341

342

343

344

345

346

347

348

349

350

351

352

353

354

355

356 modulate the immune system through connecting both adaptive and innate immune responses but also maintain the homeostasis of the host in several human diseases, from microbial infection to cancer development (Eipper et al. 2016; Habib et al. 2021; Uversky et al. 2017). It has a comparable ability to lower inflammation and positively modulate the changes associated with iron metabolism, including trafficking and storage of iron, which attributes to restoring $\mathrm{T}$ conventional lymphocytes $\left(T_{\text {conv }}\right)$ responses (Habib et al. 2021; Macciò \& Madeddu 2020).

bLF formulated in liposomes was used in two different studies on confirmed COVID-19 patients (Campione et al. 2020b; Serrano et al. 2020). Results reported by Serrano et al. showed that a liposomal bovine LF supplement containing $32 \mathrm{mg}$ of LF orally administered at 4 to 6 doses/day for 10 consecutive days, accompanied by two to three daily $10 \mathrm{mg}$ zinc doses, resulted in $100 \%$ recovery of 75 symptomatic SARS-CoV-2 positive patients within 4-5 days, and the same treatment at lower dose seemed to have prevented the disease in healthy contact (Serrano et al. 2020) $\square$. Unfortunately, that study did not offer any immunological biomarkers related to the COVID-19 infection levels before and after treatment. Campione et al. 2020b assessed the efficacy of a liposomal formulation of apo-bLF in 32 COVID-19 patients with mild-to-moderate disease and COVID-19 asymptomatic patients. The scheduled dose treatment of liposomal apo-bLF for oral use was $1 \mathrm{~g}$ per day for 30 days ( 10 capsules per day, each one containing $100 \mathrm{mg}$ of apo-bLF in liposomes) in addition to the same formulation administered intranasally 3 times daily (nasal spray contained about $2.5 \mathrm{mg} / \mathrm{ml}$ apo-bLFin liposome). On day 0,15 , and 30 of the study, rRTPCR was performed to detect the SARS-CoV-2 presence; the complete blood count and chemistry panel (liver and kidney function), iron panel, coagulation profile, IL-6, IL-10, TNF $\alpha$, and adrenomedullin serum levels were also evaluated. On day 15,10 patients $(31.25 \%)$ were clear from the SARS-CoV-2, while on day 30, all patients showed a viral clearance. On day 15, 5 patients previously symptomatic became asymptomatic, with a total of 17 asymptomatic and 15 symptomatic patients. On day 30, the other 6 patients, previously symptomatic at the 15-day period, became asymptomatic, resulting in a total of 23 asymptomatic patients (Campione et al. $2020 \mathrm{~b}$ ). Of note, these data were published as preprint during the first quarter of 2020, when many criteria concerning the COVID-19 symptoms, diagnosis methods, conversion between diseases phases, and discharge parameters were still under development. However, this report supported the suggestion that the LF could be used as an adjunctive treatment with other drugs, such as remdesivir. Another important point of study by Campione et al. 2020b is that the authors conducted in silico analysis and showed that the antiviral activity of LF can be related not only to the ability of this protein to bind to SARS-CoV-2 and cells, but also to the engagement of the LF 
357

358

359

360

361

362

363

364

365

366

367

368

369

370

371

372

373

374

375

376

377

378

379

380

381

382

383

384

385

386

387

388

389

390

391

392

393

394

395

in the direct interaction with viral spike S. Such high affinity binding of bLf to the Spike CDT1 domain can affect the attachment of $S$ to the human ACE2 receptor, and thereby alter the virus entry to the host cells (Campione et al. 2020b).

Although many functions of LF are dependent on its ability to chelate two ferric ions as well as bind anionic moieties, the multifunctionality of this protein is not entirely determined by its chelation potential, and LF is known to act as a potent anti-inflammatory and immunomodulatory molecule (Habib et al. 2021). Its anti-inflammatory activity is defined by its ability to enter the host cell via the specific receptor, followed by the translocation from the cytoplasm into the host cell nucleus. Inside the cell nucleus, LF exerts one of its main functions, regulation of the expression of various genes, including the inflammatory genes. It is able to down-regulate proinflammatory cytokines (such as IL-6, IL-12, IL-1 $\beta$, and TNF- $\alpha$ ) while D-dimer and ferritin were significantly decreased, and potentiate the adaptive immune response in vitro and in vivo models, as well as in clinical trials (Campione et al. 2020a; Campione et al. 2020b), where, for example, noticeable up-regulation of the IL-10 in COVID-19 was observed in patients after being treated with LF (Campione et al. 2020b). It is well characterized that LF is a mediator for both innate and adaptive immunity which drives the changes in the expression of local and systemic signaling molecules. This governs the balance between pro-inflammatory and anti-inflammatory, or in other words humoral and cellular, immunities. Within this complicated cross-talk, lactoferrin serves to balance/rebalance more than 93 inflammation processes associated with infections (Drago-Serrano et al. 2017; Legrand 2016).

The most interesting point in this study (Campione et al. 2020b) is that the platelet count was exponentially increased in the COVID-19 treated group. COVID-19 induces thrombocytopenia as SARS-CoV-2 seems to entrap megakaryocytes and block the release of platelets (Thachil 2020), as detailed in (Kell et al. 2020). Meanwhile, LF rebalanced the platelet count, which may enhance the COVID-19 viral clearance (Campione et al. 2020b), may increase the platelets production and activation via enhancing cathepsin $\mathrm{G}$, and consequently promote the innate immune responses during acute inflammation through cathepsin G (Eipper et al. 2016). Given that COVID-19 comorbidity patients are more susceptible to secondary infections and release LPS with its complications, it is worth noting that lactoferrin has a unique competitive binding to LPS and LPSbinding (CD14) receptors, and can directly suppress cytokine production through inhibition of $\mathrm{NF}_{\mathrm{k}} \mathrm{B}$ binding to the cytokine promoter region (Sakamoto et al. 2006; Yang et al. 2020). It exerts many functionalities through different mechanisms, i.e., interaction with extracellular matrix proteins containing Arg-Gly-Asp (RGD) such as fibronectin, and blocks its interactions with its corresponding receptor (Sakamoto et al. 2006), which represents a key molecule associated with lung function disorder in COVID-19 patients, as well as lung fibrosis (Xu et al. 2020a).

Under pathological conditions, the Myeloid-derived suppressor cells (MDSCs) are activated and are implicated in the immunological regulation of several of these pathological conditions. Although MDCSs have their distinctive gene expression and biochemical characteristics, their morphological and phenotypical characteristics are similar to neutrophils and monocytes. Often, 
396

397

398

399

400

401

402

403

404

405

406

407

408

409

410

411

412

413

414

415

416

417

418

419

420

421

422

423

424

425

426

427

428

429

430

431

432

433

434

435

MDCSs are absent or redundant under steady-state physiological conditions (He et al. 2018). The body functions of patients infected with COVID-19 orchestration are disordered, and these changes exponentially increase with the patient's age (Uversky et al. 2020a). Overall, the cluster of gene expression matrixes in the leukocytes revealed that 12 and 5 clusters are dominated in COVID-19 patient and healthy control, respectively. The MDSCs populations are significantly predominant in the critically ill COVID-19 patients, such as band neutrophils, metamyelocytes, promyelocytes-myelocytes, monocytoid precursor, and immature monocytes. These clusters were defined by many up-regulated gene expression such as (LFT, LPR-1, LPR-2, ADAM8, CD58, CR1, FCER1G, MGAM, MMP8, MMP9, S100A8/9) linked to the SARS-CoV-2 infection consequences (Vadillo et al. 2020). On the other side of LF regulatory potential, LF could bind the low-density lipoprotein receptor protein 2 (LPR-2), which is expressed on many myeloid and leukocyte cells. The myeloid cells proliferate and activate upon LF binding to its LPR-2, causing NFkB induction cascades which transform the myeloid cells into myeloid-derived suppressor cells (MDSCs) (He et al. 2018; Liu et al. 2019). The MDSCs are interesting immune homoeostatic regulatory entities, which attenuate excessive inflammation through direct regulatory cytokines (reactive oxygen ROS, nitric oxide NO, arginase, prostaglandin E2, and IL-10) or indirectly via coordination of other immune surveillance cells ( $\mathrm{T}$ regulatory lymphocyte, natural killer lymphocyte, $\mathrm{CD}^{+}$and $\mathrm{CD}^{+} \mathrm{T}$ lymphocytes, macrophages, and Dendritic cells). The more interesting issue is that LPR-2 receptor expression is age-dependent, decreasing as age increases (He et al. 2018). Recently, it was determined that LF could clearly inhibit the TLR-4/NF-KB/TNF$\alpha /$ IL-1 $\beta$ pathway components which were induced via oxygen and glucose deprivation and cerebral ischemia-reperfusion (Yang et al. 2020).

It is well-known that LF down-regulates the pro-inflammatory cytokines TNF- $\alpha$, IL-6, IL-1 $\beta$, IFN$\alpha$, and IL-8. On the other hand, when orally consumed by mice, it leads to enhanced production of Th1 immunity (IL-12, IL-18, and IFN- $\gamma$ ), which represents the main immunity against viral infection (Wakabayashi et al. 2014). It also improved the transcriptional regulation in whole blood, natural killer lymphocytes, the reduction of apoptosis in monocytes, macrophage population, and increased macrophage intracellular killing, as well as significantly up-regulated IL-10 in many human diseases and experimental models (Kawakami et al. 2015; Patras et al. 2019). Oral delivery of lactoferrin could significantly increase the production of IL-10, as well as enhance the IL-18 production in small intestine mucosa (Kawakami et al. 2015). The orally administered lactoferrin for human volunteers for 7-8 days at $100-200 \mathrm{mg}$ daily improved the production of $\mathrm{CD}^{+3}, \mathrm{CD}^{+4}$, and $\mathrm{CD}^{+8}$ lymphocytes population, and enhanced the $\mathrm{T}$ helper cells, $\mathrm{T}$ cell cytotoxic activities, natural killer cell (NK) cytotoxicity, and serum cytokine levels (Kawakami et al. 2015). It is worth noting that the IL-18 in intestinal mucosa will attribute to NK and T lymphocytes activation which works in conjunction with IFN- $\alpha$, IFN- $\beta$, and IL-12 to enhance the production of NK, T lymphocytes, and IFN- $\gamma$ (Kawakami et al. 2015). Many studies support the notion that oral intake of lactoferrin enhanced the intestine health of humans and experimental animal models, through immunological effects and influences on the host's microbiota hostage (Kawakami et al. 2015; Patras et al. 2019; Suzuki et al. 2013). This could answer the question of why children and infants 
436 have low COVID-19 morbidity and mortality, and supports the trend to orally use milk, milk 437 products, or lactoferrin for COVID-19 control, particularly since the digestive system comes right 438 the after respiratory system in infection. The density distribution of ACE2 on intestinal cells is 439 higher than that on respiratory cells( $\mathrm{Gu}$ et al. 2020).

440 LF gene ( $L T F$, lactotransferrin) expression has been previously shown to be highly up-regulated 441 in response to the SARS-CoV infection (Reghunathan et al. 2005). LF not only increases natural 442 killer cell and neutrophil activity, but also blocks viral entry through binding to heparan sulfate 443 proteoglycans. Furthermore, the ability of LF to retain anti-SARS-CoV-2 activity 24 hours post-

444

445

446

447

448

449

450

451

452

453

454

455

456

457

458

459

460

461

462

463

464

465

466

467

468

469

470

471

472

473

474 infection emphasizes the complexity of its antiviral actions exceeding simple entry inhibition (Mirabelli et al. 2020). LF also stimulates an antiviral host cell response and retains inhibitory activity in induced pluripotent stem cells (iPSC-cell line), a model for the primary site of infection. Although a definitive and complete mechanism of anti-SARS-CoV-2 LF action was not determined, it was shown that, upon treatment with LF, the host cell undergoes significant modulation through increased expression of several interferon-stimulated genes where a dosedependent reduction of SARS-CoV-2 replication was observed, which was consistent with the elevated mRNA levels of IFN- $\beta$ and interferon-stimulated genes (ISG15, MX1, RSAD2 (Viperin), and IFITM3) in LF-treated Huh7 cells (Mirabelli et al. 2020).

Previously, LF was shown to decrease the production of IL-6 (Cutone et al. 2014), which is one of the key players of the "cytokine storm" produced by SARS-CoV-2 infection (Conti et al. 2020; Lagunas-Rangel \& Chávez-Valencia 2020). It was found that LF, either of bovine or human origin, retained antiviral activity in both the holo- and apo- forms, with the latter being the component of the orally available LF supplement. LF's potential is further heightened by its ability to mitigate a high multiplicity of infection (MOI, which refers to the number of virions that are added per cell during infection) during a SARS-CoV-2 infection. As ACE2 receptors are highly expressed on the gastrointestinal tissues, the orally available LF could be especially effective in resolving the gastrointestinal (GI) symptoms that are present in COVID-19 patients (Han et al. 2020). The mechanisms may be similar to the mechanisms by which LF reduces human norovirus infection through induction of innate immune responses (Oda et al. 2020). In line with these observations, it was pointed out that the $L T F$ gene polymorphisms are associated with an increased susceptibility of patients to infectious diarrhea (Mohamed et al. 2007). If LF reduces viral load in the GI tract, it could reduce fecal-oral transmission of SARS-CoV-2 (Gu et al. 2020). Furthermore, the orally consumed LF offers another interesting way of suppression of the viral infection, where the pepsindigested LF derivative (highly positively charged loop domain) is generated, which has an antiviral activity more than 10-fold higher than those of the full-length LF or its N-lobe (Berlutti et al. 2011).

\section{Conclusions}

Lactoferrin has a long history as an antiviral chelating agent. It works directly or indirectly on the viral molecules and is available at the market for several health purposes. Currently, 142 clinical 
475 trials include LF (Campione et al. 2020a). The observed antiviral action of LF can be, at least in 476 part, attributed to an efficient competition between ACE2 and LF for the binding to the SARS477 CoV-2 spike protein (Miotto et al. 2020). It seems that SARS-CoV-2 uses a dual hit strategy, with 478 its spike protein being able to interact with sialic acid and ACE2 receptors on the cell's surface 479 (Milanetti et al. 2020). This mechanism, where the first step concentrates the viral particles on the 480 cell surface thereby facilitating the virus localization in the vicinity of the ACE2, may have

481

482

483

484

485

486

487

488

489

490

491

492

493

494

495

496

497

498

499

500

501

502

503

504

505

506

507

508

509

510

511

512

513

514

515

516 explained the high infectivity potential of SARS-CoV-2 (Elrashdy et al. 2020c; Uversky et al. 2020b). This hypothesis is supported by the Hu el al. 2021 reporting model of heparin docking to bLF (Hu et al. 2021). LF binds to cell surface HSPGs, which blocks the interaction between SARSCoV-2 and HSPGs and subsequent viral attachment to host cells. LF can successfully oppose infectivity by binding to HS-PG and SIA-PG, or by direct binding to the spike protein (see Figure 3). Furthermore, there are also multiple mechanisms by which LF might affect the antiviral immune response. There are thousands of suggestions for combination treatments of COVID-19. Given its limited cost, lack of adverse effects, and wide availability, LF could be an effective and rapidly deployable option for both prophylaxis and the management of COVID-19 (Mirabelli et al. 2020).

\section{Acknowledgements}

The authors extend their appreciation to the Deputyship for Research \& Innovation, Ministry of Education in Saudi Arabia for funding this research work through the project number (838).

\section{References}

Abd El-Salam M, and El-Shibiny S. 2012. Bioactive Peptides of Buffalo, Camel, Goat, Sheep, Mare, and Yak Milks and Milk Products. Food Reviews International - FOOD REV INT 29. 10.1080/87559129.2012.692137

Albar AH, Almehdar HA, Uversky VN, and Redwan EM. 2014. Structural heterogeneity and multifunctionality of lactoferrin. Curr Protein Pept Sci 15:778-797. 10.2174/1389203715666140919124530

Berlutti F, Pantanella F, Natalizi T, Frioni A, Paesano R, Polimeni A, and Valenti P. 2011. Antiviral properties of lactoferrin--a natural immunity molecule. Molecules 16:6992-7018. 10.3390/molecules 16086992

Burckhardt CJ, and Greber UF. 2009. Virus movements on the plasma membrane support infection and transmission between cells. PLoS Pathog 5:e1000621. 10.1371/journal.ppat.1000621

Campione E, Cosio T, Rosa L, Lanna C, Di Girolamo S, Gaziano R, Valenti P, and Bianchi L. 2020a. Lactoferrin as Protective Natural Barrier of Respiratory and Intestinal Mucosa against Coronavirus Infection and Inflammation. Int J Mol Sci 21. 10.3390/ijms21144903

Campione E, Lanna C, Cosio T, Rosa L, Conte MP, lacovelli F, Romeo A, Falconi M, Del Vecchio C, Franchin E, Lia MS, Minieri M, Chiaramonte C, Ciotti M, Nuccetelli M, Terrinoni A, lannuzzi I, Coppeda L, Magrini A, Moricca N, Sabatini S, Rosapepe F, Bartoletti PL, Bernardini S, Andreoni M, Valenti P, and Bianchi L. 2020b. Pleiotropic effect of Lactoferrin in the prevention and treatment of COVID-19 infection: 
517

518

519

520

521

522

523

524

525

526

527

528

529

530

531

532

533

534

535

536

537

538

539

540

541

542

543

544

545

546

547

548

549

550

551

552

553

554

555

556

557

558

559

560

561

562

563

564

565

$<$ em>randomized clinical trial, in vitro and in silico</em> preliminary evidences. bioRxiv:2020.2008.2011.244996. 10.1101/2020.08.11.244996

Chang R, Ng TB, and Sun WZ. 2020. Lactoferrin as potential preventative and adjunct treatment for COVID-19. Int J Antimicrob Agents 56:106118. 10.1016/j.ijantimicag.2020.106118

Chien YJ, Chen WJ, Hsu WL, and Chiou SS. 2008. Bovine lactoferrin inhibits Japanese encephalitis virus by binding to heparan sulfate and receptor for low density lipoprotein. Virology 379:143-151. 10.1016/j.virol.2008.06.017

Cockburn DW, and Koropatkin NM. 2016. Polysaccharide Degradation by the Intestinal Microbiota and Its Influence on Human Health and Disease. J Mol Biol 428:3230-3252. 10.1016/j.jmb.2016.06.021

Conesa C, Sanchez L, Rota C, Perez MD, Calvo M, Farnaud S, and Evans RW. 2008. Isolation of lactoferrin from milk of different species: calorimetric and antimicrobial studies. Comp Biochem Physiol B Biochem Mol Biol 150:131-139. 10.1016/j.cbpb.2008.02.005

Conti P, Ronconi G, Caraffa A, Gallenga CE, Ross R, Frydas I, and Kritas SK. 2020. Induction of pro-inflammatory cytokines (IL-1 and IL-6) and lung inflammation by Coronavirus-19 (COVI-19 or SARS-CoV-2): anti-inflammatory strategies. J Biol Regul Homeost Agents 34:327-331. 10.23812/conti-e

Conzelmann C, Zou M, Groß R, Harms M, Röcker A, Riedel CU, Münch J, and Müller JA. 2019. Storage-Dependent Generation of Potent Anti-ZIKV Activity in Human Breast Milk. Viruses 11. 10.3390/v11070591

Costagliola G, Spada E, Comberiati P, and Peroni DG. 2021. Could nutritional supplements act as therapeutic adjuvants in COVID-19? Ital J Pediatr 47:32. 10.1186/s13052-021-009900

Cutone A, Frioni A, Berlutti F, Valenti P, Musci G, and Bonaccorsi di Patti MC. 2014. Lactoferrin prevents LPS-induced decrease of the iron exporter ferroportin in human monocytes/macrophages. Biometals 27:807-813. 10.1007/s10534-014-9742-7

Dave LA, Hayes M, Montoya CA, Rutherfurd SM, and Moughan PJ. 2016. Human gut endogenous proteins as a potential source of angiotensin-l-converting enzyme (ACE-I)-, renin inhibitory and antioxidant peptides. Peptides 76:30-44. 10.1016/j.peptides.2015.11.003

de Carvalho CAM, da Rocha Matos A, Caetano BC, de Sousa Junior IP, da Costa Campos SP, Geraldino BR, Barros CA, de Almeida MAP, Rocha VP, da Silva AMV, Melgaço JG, da Costa Neves PC, da Costa Barros TA, Ano Bom APD, Siqueira MM, Missailidis S, and Gonçalves RB. 2020. In Vitro Inhibition of SARS-CoV-2 Infection by Bovine Lactoferrin. bioRxiv:2020.2005.2013.093781. 10.1101/2020.05.13.093781

Drago-Serrano ME, Campos-Rodríguez R, Carrero JC, and de la Garza M. 2017. Lactoferrin: Balancing Ups and Downs of Inflammation Due to Microbial Infections. Int J Mol Sci 18. 10.3390/ijms18030501

Eipper S, Steiner R, Lesner A, Sienczyk M, Palesch D, Halatsch ME, Zaczynska E, Heim C, Hartmann MD, Zimecki M, Wirtz CR, and Burster T. 2016. Lactoferrin Is an Allosteric Enhancer of the Proteolytic Activity of Cathepsin G. PLoS One 11:e0151509. 10.1371/journal.pone.0151509

Ejemel M, Li Q, Hou S, Schiller ZA, Wallace AL, Amcheslavsky A, Yilmaz NK, Toomey JR, Schneider R, Close BJ, Chen DY, Conway HL, Mohsan S, Cavacini LA, Klempner MS, Schiffer CA, and Wang Y. 2020. IgA MAb blocks SARS-CoV-2 Spike-ACE2 interaction providing mucosal immunity. bioRxiv. 10.1101/2020.05.15.096719

El-Agamy El. 2006. Camel milk. In: Park YW, and Haenlan GFW, eds. Handbook of Milk of Non-Bovine Mammals. Hoboken, New Jersey, USA: Wiley-Blackwell.

Peer) reviewing PDF | (2021:01:57322:1:0:NEW 13 Mar 2021) 
566

567

568

569

570

571

572

573

574

575

576

577

578

579

580

581

582

583

584

585

586

587

588

589

590

591

592

593

594

595

596

597

598

599

600

601

602

603

604

605

606

607

608

609

610

611

612

613

614

615

El-Fakharany EM, Abedelbaky N, Haroun BM, Sanchez L, Redwan NA, and Redwan EM. 2012. Anti-infectivity of camel polyclonal antibodies against hepatitis $\mathrm{C}$ virus in Huh7.5 hepatoma. Virol J 9:201. 10.1186/1743-422X-9-201

El-Fakharany EM, El-Baky NA, Linjawi MH, Aljaddawi AA, Saleem TH, Nassar AY, Osman A, and Redwan EM. 2017. Influence of camel milk on the hepatitis $C$ virus burden of infected patients. Exp Ther Med 13:1313-1320. 10.3892/etm.2017.4159

El-Fakharany EM, Sanchez L, Al-Mehdar HA, and Redwan EM. 2013. Effectiveness of human, camel, bovine and sheep lactoferrin on the hepatitis $C$ virus cellular infectivity: comparison study. Virol J 10:199. 10.1186/1743-422x-10-199

Elrashdy F, Aljaddawi AA, Redwan EM, and Uversky VN. 2020a. On the potential role of exosomes in the COVID-19 reinfection/reactivation opportunity. J Biomol Struct Dyn:112. $10.1080 / 07391102.2020 .1790426$

Elrashdy F, Redwan EM, and Uversky VN. 2020b. Intrinsic disorder perspective of an interplay between the renin-angiotensin-aldosterone system and SARS-CoV-2. Infect Genet Evol 85:104510. 10.1016/j.meegid.2020.104510

Elrashdy F, Redwan EM, and Uversky VN. 2020c. Why COVID-19 Transmission Is More Efficient and Aggressive Than Viral Transmission in Previous Coronavirus Epidemics? Biomolecules 10. 10.3390/biom10091312

Fan H, Luo Y, Hong B, Wang L, Jin X, Chen Y, Hu Y, Li T, Zhuang H, Zhou Y-H, Tong Y, and Xiang K. 2020. The effect of whey protein on viral infection and replication of SARSCoV-2 and pangolin coronavirus in vitro. bioRxiv:2020.2008.2017.254979. 10.1101/2020.08.17.254979

Figueroa-Lozano S, Valk-Weeber RL, Akkerman R, Abdulahad W, van Leeuwen SS, Dijkhuizen L, and de Vos P. 2020. Inhibitory Effects of Dietary N-Glycans From Bovine Lactoferrin on Toll-Like Receptor 8; Comparing Efficacy With Chloroquine. Front Immunol 11:790. 10.3389/fimmu.2020.00790

Figueroa-Lozano S, Valk-Weeber RL, van Leeuwen SS, Dijkhuizen L, and de Vos P. 2018. Dietary N-Glycans from Bovine Lactoferrin and TLR Modulation. Mol Nutr Food Res 62. 10.1002/mnfr.201700389

Groot F, Geijtenbeek TB, Sanders RW, Baldwin CE, Sanchez-Hernandez M, Floris R, van Kooyk Y, de Jong EC, and Berkhout B. 2005. Lactoferrin prevents dendritic cellmediated human immunodeficiency virus type 1 transmission by blocking the DC-SIGN-gp120 interaction. J Virol 79:3009-3015. 10.1128/jvi.79.5.3009-3015.2005

Gu J, Han B, and Wang J. 2020. COVID-19: Gastrointestinal Manifestations and Potential Fecal-Oral Transmission. Gastroenterology 158:1518-1519.

10.1053/j.gastro.2020.02.054

Habib HM, Ibrahim S, Zaim A, and Ibrahim WH. 2021. The role of iron in the pathogenesis of COVID-19 and possible treatment with lactoferrin and other iron chelators. Biomed Pharmacother 136:111228. 10.1016/j.biopha.2021.111228

Han C, Duan C, Zhang S, Spiegel B, Shi H, Wang W, Zhang L, Lin R, Liu J, Ding Z, and Hou X. 2020. Digestive Symptoms in COVID-19 Patients With Mild Disease Severity: Clinical Presentation, Stool Viral RNA Testing, and Outcomes. Am J Gastroenterol 115:916-923. 10.14309/ajg.0000000000000664

Han N, Li H, Li G, Shen Y, Fei M, and Nan Y. 2019. Effect of bovine lactoferrin as a novel therapeutic agent in a rat model of sepsis-induced acute lung injury. AMB Express 9:177. 10.1186/s13568-019-0900-8

He Y, Lawlor NT, and Newburg DS. 2016. Human Milk Components Modulate Toll-Like Receptor-Mediated Inflammation. Adv Nutr 7:102-111. 10.3945/an.115.010090

He YM, Li X, Perego M, Nefedova Y, Kossenkov AV, Jensen EA, Kagan V, Liu YF, Fu SY, Ye QJ, Zhou YH, Wei L, Gabrilovich DI, and Zhou J. 2018. Transitory presence of myeloid- 
616

617

618

619

620

621

622

623

624

625

626

627

628

629

630

631

632

633

634

635

636

637

638

639

640

641

642

643

644

645

646

647

648

649

650

651

652

653

654

655

656

657

658

659

660

661

662

663

664

665

666 derived suppressor cells in neonates is critical for control of inflammation. Nat Med 24:224-231. 10.1038/nm.4467

Hoffmann M, Kleine-Weber H, Schroeder S, Krüger N, Herrler T, Erichsen S, Schiergens TS, Herrler G, Wu NH, Nitsche A, Müller MA, Drosten C, and Pöhlmann S. 2020. SARSCoV-2 Cell Entry Depends on ACE2 and TMPRSS2 and Is Blocked by a Clinically Proven Protease Inhibitor. Cell 181:271-280.e278. 10.1016/j.cell.2020.02.052

Hu Y, Meng X, Zhang F, Xiang Y, and Wang J. 2021. The in vitro antiviral activity of lactoferrin against common human coronaviruses and SARS-CoV-2 is mediated by targeting the heparan sulfate co-receptor. Emerg Microbes Infect:1-32. 10.1080/22221751.2021.1888660

Karl JP. 2021. Gut Microbiota-targeted Interventions for Reducing the Incidence, Duration, and Severity of Respiratory Tract Infections in Healthy Non-elderly Adults. Mil Med 186:e310e318. 10.1093/milmed/usaa261

Kawakami H, Park H, Park S, Kuwata H, Shephard RJ, and Aoyagi Y. 2015. Effects of entericcoated lactoferrin supplementation on the immune function of elderly individuals: $A$ randomised, double-blind, placebo-controlled trial. International Dairy Journal 47:79-85. https://doi.org/10.1016/j.idairyj.2015.02.001

Kell DB, Heyden EL, and Pretorius E. 2020. The Biology of Lactoferrin, an Iron-Binding Protein That Can Help Defend Against Viruses and Bacteria. Frontiers in Immunology 11. 10.3389/fimmu.2020.01221

Khan JA, Kumar P, Paramasivam M, Yadav RS, Sahani MS, Sharma S, Srinivasan A, and Singh TP. 2001. Camel lactoferrin, a transferrin-cum-lactoferrin: crystal structure of camel apolactoferrin at 2.6 A resolution and structural basis of its dual role. $\mathrm{J} \mathrm{Mol} \mathrm{Biol}$ 309:751-761. 10.1006/jmbi.2001.4692

Konishi M, Iwasa M, Yamauchi K, Sugimoto R, Fujita N, Kobayashi Y, Watanabe S, Teraguchi S, Adachi Y, and Kaito M. 2006. Lactoferrin inhibits lipid peroxidation in patients with chronic hepatitis C. Hepatol Res 36:27-32. 10.1016/j.hepres.2006.06.005

Lagunas-Rangel FA, and Chávez-Valencia V. 2020. High IL-6/IFN-y ratio could be associated with severe disease in COVID-19 patients. J Med Virol. 10.1002/jmv.25900

Lang J, Yang N, Deng J, Liu K, Yang P, Zhang G, and Jiang C. 2011. Inhibition of SARS pseudovirus cell entry by lactoferrin binding to heparan sulfate proteoglycans. PLoS One 6:e23710. 10.1371/journal.pone.0023710

Legrand D. 2016. Overview of Lactoferrin as a Natural Immune Modulator. J Pediatr 173 Suppl:S10-15. 10.1016/j.jpeds.2016.02.071

Legrand D, Pierce A, Elass E, Carpentier M, Mariller C, and Mazurier J. 2008. Lactoferrin structure and functions. Adv Exp Med Biol 606:163-194. 10.1007/978-0-387-74087-4_6

Liao Y, El-Fakkarany E, Lonnerdal B, and Redwan EM. 2012. Inhibitory effects of native and recombinant full-length camel lactoferrin and its $\mathrm{N}$ and $\mathrm{C}$ lobes on hepatitis $\mathrm{C}$ virus infection of Huh7.5 cells. J Med Microbiol 61:375-383. 10.1099/jmm.0.033894-0

Liu W, Liu Y, Liu Z, Hong C, Liu J, Luo S, and Zheng X. 2021. A Case Study Supporting Lack of SARS-CoV-2 Spread to a 3-Month Old Infant Through Exclusive Breastfeeding. J Hum Lact:890334421991072. 10.1177/0890334421991072

Liu Y, Perego M, Xiao Q, He Y, Fu S, He J, Liu W, Li X, Tang Y, Li X, Yuan W, Zhou W, Wu F, Jia C, Cui Q, Worthen GS, Jensen EA, Gabrilovich DI, and Zhou J. 2019. Lactoferrininduced myeloid-derived suppressor cell therapy attenuates pathologic inflammatory conditions in newborn mice. J Clin Invest 129:4261-4275. 10.1172/jci128164

Llorente García I, and Marsh M. 2020. A biophysical perspective on receptor-mediated virus entry with a focus on HIV. Biochim Biophys Acta Biomembr 1862:183158. 10.1016/j.bbamem.2019.183158

Lonnerdal B. 2009. Nutritional roles of lactoferrin. Curr Opin Clin Nutr Metab Care 12:293-297. 10.1097/MCO.0b013e328328d13e 
667

668

669

670

671

672

673

674

675

676

677

678

679

680

681

682

683

684

685

686

687

688

689

690

691

692

693

694

695

696

697

698

699

700

701

702

703

704

705

706

707

708

709

710

711

712

713

714

715

716

Macciò A, and Madeddu C. 2020. Blocking inflammation to improve immunotherapy of advanced cancer. Immunology 159:357-364. 10.1111/imm.13164

Madadlou A. 2020. Food proteins are a potential resource for mining cathepsin L inhibitory drugs to combat SARS-CoV-2. Eur J Pharmacol 885:173499. 10.1016/j.ejphar.2020.173499

Milanetti E, Miotto M, Rienzo L, Monti M, Gosti G, and Ruocco G. 2020. In-Silico evidence for two receptors based strategy of SARS-CoV-2.

Miotto M, Rienzo L, Bò L, Boffi A, Ruocco G, and Milanetti E. 2020. Molecular mechanisms behind anti SARS-CoV-2 action of lactoferrin.

Mirabelli C, Wotring JW, Zhang CJ, McCarty SM, Fursmidt R, Frum T, Kadambi NS, Amin AT, O'Meara TR, Pretto CD, Spence JR, Huang J, Alysandratos KD, Kotton DN, Handelman SK, Wobus CE, Weatherwax KJ, Mashour GA, O'Meara MJ, and Sexton JZ. 2020. Morphological Cell Profiling of SARS-CoV-2 Infection Identifies Drug Repurposing Candidates for COVID-19. bioRxiv:2020.2005.2027.117184. 10.1101/2020.05.27.117184

Mitoulas LR, Schärer-Hernández NG, and Liabat S. 2020. Breastfeeding, Human Milk and COVID-19-What Does the Evidence Say? Front Pediatr 8:613339. 10.3389/fped.2020.613339

Mohamed JA, DuPont HL, Jiang ZD, Belkind-Gerson J, Figueroa JF, Armitige LY, Tsai A, Nair P, Martinez-Sandoval FJ, Guo DC, Hayes P, and Okhuysen PC. 2007. A novel singlenucleotide polymorphism in the lactoferrin gene is associated with susceptibility to diarrhea in North American travelers to Mexico. Clin Infect Dis 44:945-952. $10.1086 / 512199$

Oda H, Kolawole AO, Mirabelli C, Wakabayashi H, Tanaka M, Yamauchi K, Abe F, and Wobus CE. 2020. Antiviral Effects of Bovine Lactoferrin on Human Norovirus. Biochem Cell Biol. 10.1139/bcb-2020-0035

Ostan NKH, Moraes TF, and Schryvers AB. 2021. Lactoferrin receptors in Gram-negative bacteria: an evolutionary perspective. Biochem Cell Biol 99:102-108. 10.1139/bcb-20200079

Ou X, Liu Y, Lei X, Li P, Mi D, Ren L, Guo L, Guo R, Chen T, Hu J, Xiang Z, Mu Z, Chen X, Chen J, Hu K, Jin Q, Wang J, and Qian Z. 2020. Characterization of spike glycoprotein of SARS-CoV-2 on virus entry and its immune cross-reactivity with SARS-CoV. Nat Commun 11:1620. 10.1038/s41467-020-15562-9

Patras KA, Ha AD, Rooholfada E, Olson J, Ramachandra Rao SP, Lin AE, and Nizet V. 2019. Augmentation of Urinary Lactoferrin Enhances Host Innate Immune Clearance of Uropathogenic Escherichia coli. J Innate Immun 11:481-495. 10.1159/000499342

Puddu P, Borghi P, Gessani S, Valenti P, Belardelli F, and Seganti L. 1998. Antiviral effect of bovine lactoferrin saturated with metal ions on early steps of human immunodeficiency virus type 1 infection. Int J Biochem Cell Biol 30:1055-1062. 10.1016/s13572725(98)00066-1

Rahimi M, Ghaffari SM, Salami M, Mousavy SJ, Niasari-Naslaji A, Jahanbani R, Yousefinejad S, Khalesi M, and Moosavi-Movahedi AA. 2016. ACE- inhibitory and radical scavenging activities of bioactive peptides obtained from camel milk casein hydrolysis with proteinase K. Dairy Science \& Technology 96:489-499. 10.1007/s13594-016-0283-4

Rai AK, Sanjukta S, and Jeyaram K. 2017. Production of angiotensin I converting enzyme inhibitory (ACE-I) peptides during milk fermentation and their role in reducing hypertension. Crit Rev Food Sci Nutr 57:2789-2800. 10.1080/10408398.2015.1068736

Ramani S, Stewart CJ, Laucirica DR, Ajami NJ, Robertson B, Autran CA, Shinge D, Rani S, Anandan S, Hu L, Ferreon JC, Kuruvilla KA, Petrosino JF, Venkataram Prasad BV, Bode L, Kang G, and Estes MK. 2018. Human milk oligosaccharides, milk microbiome and

Peer) reviewing PDF | (2021:01:57322:1:0:NEW 13 Mar 2021) 
717

718

719

720

721

722

723

724

725

726

727

728

729

730

731

732

733

734

735

736

737

738

739

740

741

742

743

744

745

746

747

748

749

750

751

752

753

754

755

756

757

758

759

760

761

762

763

764

765

766

infant gut microbiome modulate neonatal rotavirus infection. Nat Commun 9:5010. 10.1038/s41467-018-07476-4

Redwan el RM, and Tabll A. 2007. Camel lactoferrin markedly inhibits hepatitis C virus genotype 4 infection of human peripheral blood leukocytes. J Immunoassay Immunochem 28:267-277. 10.1080/15321810701454839

Redwan EM, El-Fakharany EM, Uversky VN, and Linjawi MH. 2014a. Screening the anti infectivity potentials of native $\mathrm{N}$ - and $\mathrm{C}$-lobes derived from the camel lactoferrin against hepatitis C virus. BMC Complement Altern Med 14:219. 10.1186/1472-6882-14-219

Redwan EM, Uversky VN, El-Fakharany EM, and Al-Mehdar H. 2014b. Potential lactoferrin activity against pathogenic viruses. C R Biol 337:581-595. 10.1016/j.crvi.2014.08.003

Reghunathan R, Jayapal M, Hsu LY, Chng HH, Tai D, Leung BP, and Melendez AJ. 2005. Expression profile of immune response genes in patients with Severe Acute Respiratory Syndrome. BMC Immunol 6:2. 10.1186/1471-2172-6-2

Ren G, Cheng G, and Wang J. 2021. Understanding the role of milk in regulating human homeostasis in the context of the COVID-19 global pandemic. Trends Food Sci Technol 107:157-160. 10.1016/j.tifs.2020.09.027

Saidi H, Eslahpazir J, Carbonneil C, Carthagena L, Requena M, Nassreddine N, and Belec L. 2006. Differential modulation of human lactoferrin activity against both R5 and X4-HIV-1 adsorption on epithelial cells and dendritic cells by natural antibodies. J Immunol 177:5540-5549. 10.4049/jimmunol.177.8.5540

Sakamoto K, Ito Y, Mori T, and Sugimura K. 2006. Interaction of human lactoferrin with cell adhesion molecules through RGD motif elucidated by lactoferrin-binding epitopes. $J$ Biol Chem 281:24472-24478. 10.1074/jbc.M604974200

Salaris C, Scarpa M, Elli M, Bertolini A, Guglielmetti S, Pregliasco F, Blandizzi C, Brun P, and Castagliuolo I. 2021. Protective Effects of Lactoferrin against SARS-CoV-2 Infection In Vitro. Nutrients 13. 10.3390/nu13020328

Sano E, Miyauchi R, Takakura N, Yamauchi K, Murata E, Le QT, and Katunuma N. 2005. Cysteine protease inhibitors in various milk preparations and its importance as a food. Food Research International 38:427-433. https://doi.org/10.1016/j.foodres.2004.10.011

Sano H, Nagai K, Tsutsumi H, and Kuroki Y. 2003. Lactoferrin and surfactant protein A exhibit distinct binding specificity to $\mathrm{F}$ protein and differently modulate respiratory syncytial virus infection. Eur J Immunol 33:2894-2902. 10.1002/eji.200324218

Serrano G, Kochergina I, Albors A, Eva Diaz E, Oroval M, Hueso G, and Serrano JM. 2020. Liposomal lacfoferrin as potential prevention and cure for COVID-19. Int $J$ Res Health Sci 8:8-15. 10.5530/ijrhs.8.1.3

Shute JK, Calzetta L, Cardaci V, di Toro S, Page CP, and Cazzola M. 2018. Inhaled nebulised unfractionated heparin improves lung function in moderate to very severe COPD: A pilot study. Pulm Pharmacol Ther 48:88-96. 10.1016/j.pupt.2017.10.001

Superti F, Ammendolia MG, Valenti P, and Seganti L. 1997. Antirotaviral activity of milk proteins: lactoferrin prevents rotavirus infection in the enterocyte-like cell line HT-29. Med Microbiol Immunol 186:83-91. 10.1007/s004300050049

Suzuki N, Murakoshi M, Ono T, Morishita S, Koide M, Bae MJ, Totsuka M, Shimizu M, Sugiyama K, Nishino H, and lida N. 2013. Effects of Enteric-coated Lactoferrin Tablets Containing Lactobacillus brevis subsp. coagulans on Fecal Properties, Defecation Frequency and Intestinal Microbiota of Japanese Women with a Tendency for Constipation: a Randomized Placebo-controlled Crossover Study. Biosci Microbiota Food Health 32:13-21. 10.12938/bmfh.32.13

Tanji H, Ohto U, Shibata T, Taoka M, Yamauchi Y, Isobe T, Miyake K, and Shimizu T. 2015. Toll-like receptor 8 senses degradation products of single-stranded RNA. Nat Struct Mol Biol 22:109-115. 10.1038/nsmb.2943

Peer] reviewing PDF | (2021:01:57322:1:0:NEW 13 Mar 2021) 
767

768

769

770

771

772

773

774

775

776

777

778

779

780

781

782

783

784

785

786

787

788

789

790

791

792

793

794

795

796

797

798

799

800

801

802

803

804

805

806

807

808

809

810

811

812

813

814

815

816

817

Thachil J. 2020. What do monitoring platelet counts in COVID-19 teach us? J Thromb Haemost 18:2071-2072. 10.1111/jth. 14879

Tinari A, Pietrantoni A, Ammendolia MG, Valenti P, and Superti F. 2005. Inhibitory activity of bovine lactoferrin against echovirus induced programmed cell death in vitro. Int $J$ Antimicrob Agents 25:433-438. 10.1016/j.ijantimicag.2005.02.011

Triantis V, Bode L, and van Neerven RJJ. 2018. Immunological Effects of Human Milk Oligosaccharides. Front Pediatr 6:190. 10.3389/fped.2018.00190

Uversky V, Elrashdy F, Aljadawi A, Ali S, Khan RH, and Redwan E. 2020a. SARS-CoV-2 Infection Reaches the Human Nervous System: How?

Uversky VN, El-Fakharany EM, Abu-Serie MM, Almehdar HA, and Redwan EM. 2017. Divergent Anticancer Activity of Free and Formulated Camel Milk a-Lactalbumin. Cancer Invest 35:610-623. 10.1080/07357907.2017.1373783

Uversky VN, Elrashdy F, Aljadawi A, and Redwan EM. 2020b. Household pets and SARS-CoV2 transmissibility in the light of the ACE2 intrinsic disorder status. J Biomol Struct Dyn:1-4. 10.1080/07391102.2020.1821784

Vadillo E, Taniguchi-Ponciano K, Lopez-Macias C, Carvente-Garcia R, Mayani H, Ferat-Osorio E, Flores-Padilla G, Torres J, Gonzalez-Bonilla CR, Majluf A, Albarran-Sanchez A, Galan JC, Peña-Martínez E, Silva-Román G, Vela-Patiño S, Ferreira-Hermosillo A, Ramirez-Renteria C, Espinoza-Sanchez NA, Pelayo-Camacho R, Bonifaz L, ArriagaPizano L, Mata-Lozano C, Andonegui-Elguera S, Wacher N, Blanco-Favela F, De-LiraBarraza R, Villanueva-Compean H, Esquivel-Pineda A, Ramírez-Montes-de-Oca R, Anda-Garay C, Noyola-García M, Guizar-García L, Cerbulo-Vazquez A, Zamudio-Meza H, Marrero-Rodríguez D, and Mercado M. 2020. A Shift Towards an Immature Myeloid Profile in Peripheral Blood of Critically III COVID-19 Patients. Arch Med Res. 10.1016/j.arcmed.2020.11.005

Valenti P, and Antonini G. 2005. Lactoferrin: an important host defence against microbial and viral attack. Cell Mol Life Sci 62:2576-2587. 10.1007/s00018-005-5372-0

Wada $Y$, and Lönnerdal B. 2020. Bioactive peptides derived from human milk proteins: an update. Curr Opin Clin Nutr Metab Care 23:217-222. 10.1097/mco.0000000000000642

Wakabayashi H, Oda H, Yamauchi K, and Abe F. 2014. Lactoferrin for prevention of common viral infections. J Infect Chemother 20:666-671. 10.1016/j.jiac.2014.08.003

Wang Y, Wang P, Wang H, Luo Y, Wan L, Jiang M, and Chu Y. 2020. Lactoferrin for the treatment of COVID-19 (Review). Exp Ther Med 20:272. 10.3892/etm.2020.9402

Wettstein L, Conzelmann C, Müller JA, Weil T, Groß R, Hirschenberger M, Seidel A, Klute S, Zech F, Bozzo CP, Preising N, Fois G, Lochbaum R, Knaff P, Mailänder V, Ständker L, Thal DR, Schumann C, Stenger S, Kleger A, Lochnit G, Sparrer K, Kirchhoff F, Frick M, and Münch J. 2020. Alpha-1 antitrypsin inhibits SARS-CoV-2 infection. bioRxiv:2020.2007.2002.183764. 10.1101/2020.07.02.183764

Xu J, Xu X, Jiang L, Dua K, Hansbro PM, and Liu G. 2020a. SARS-CoV-2 induces transcriptional signatures in human lung epithelial cells that promote lung fibrosis. Respir Res 21:182. 10.1186/s12931-020-01445-6

Xu S, Fan F, Liu H, Cheng S, Tu M, and Du M. 2020b. Novel Anticoagulant Peptide from Lactoferrin Binding Thrombin at the Active Site and Exosite-I. J Agric Food Chem 68:3132-3139. 10.1021/acs.jafc.9b08094

Yahya MA, Alhaj OA, and Al-Khalifah AS. 2017. Antihypertensive effect of fermented skim camel (Camelus dromedarius) milk on spontaneously hypertensive rats. Nutr Hosp 34:416-421. 10.20960/nh.1163

Yang HG, Li HY, Li P, Bao XY, Huang GX, Xing L, Zheng N, and Wang JQ. 2020. Modulation activity of heat-treated and untreated lactoferrin on the TLR-4 pathway in anoxia cell model and cerebral ischemia reperfusion mouse model. J Dairy Sci 103:1151-1163. 10.3168/jds.2019-17002

Peer) reviewing PDF | (2021:01:57322:1:0:NEW 13 Mar 2021) 
818 Yi M, Kaneko S, Yu DY, and Murakami S. 1997. Hepatitis C virus envelope proteins bind

$819 \quad$ lactoferrin. J Virol 71:5997-6002. 10.1128/jvi.71.8.5997-6002.1997

820 Zwirzitz A, Reiter M, Skrabana R, Ohradanova-Repic A, Majdic O, Gutekova M, Cehlar O,

821

822 Petrovčíková E, Kutejova E, Stanek G, Stockinger H, and Leksa V. 2018. Lactoferrin is a natural inhibitor of plasminogen activation. J Biol Chem 293:8600-8613.

823 10.1074/jbc.RA118.003145

824

825

826

827

828

829

830 


\section{Figure 1}

Figure 1. General scenarios for the evaluation of in vitro Lf potential against virus (S1S3).

Each scenario has a specific incubation time. These in vitro evaluation scenarios were used for the analysis of HCV, SARS-CoV-2 and many others viruses. They can be used to analyze the antiviral activities of Lf with different cell lines and/or under different experimental conditions.

$\mathrm{S} 1$

Protection

Lactoferrin, $60 \mathrm{~min}$ at $37^{\circ} \mathrm{C}$

Cell-lines $\stackrel{\text { Incubation }}{\longrightarrow}$ was

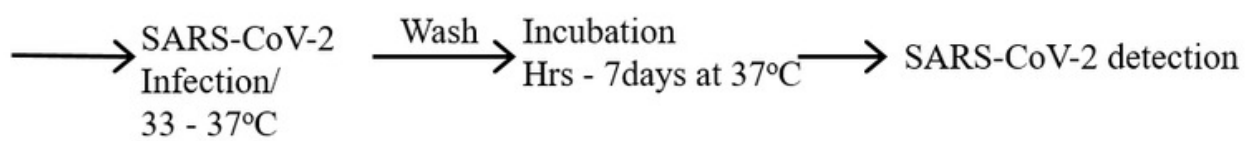

S2

Neutralization

Lactoferrin, $60 \mathrm{~min}$ at $4^{\circ} \mathrm{C}$

SARS-CoV-2 Incubation

Lactoferrin

$60-$ hrs $\min$ at $37^{\circ} \mathrm{C}$

Hrs - 7 days at $37^{\circ} \mathrm{C}$

$5 \% \mathrm{CO}_{2}$

SARS-CoV-2 detection

S3

Treatment

Viral Infection

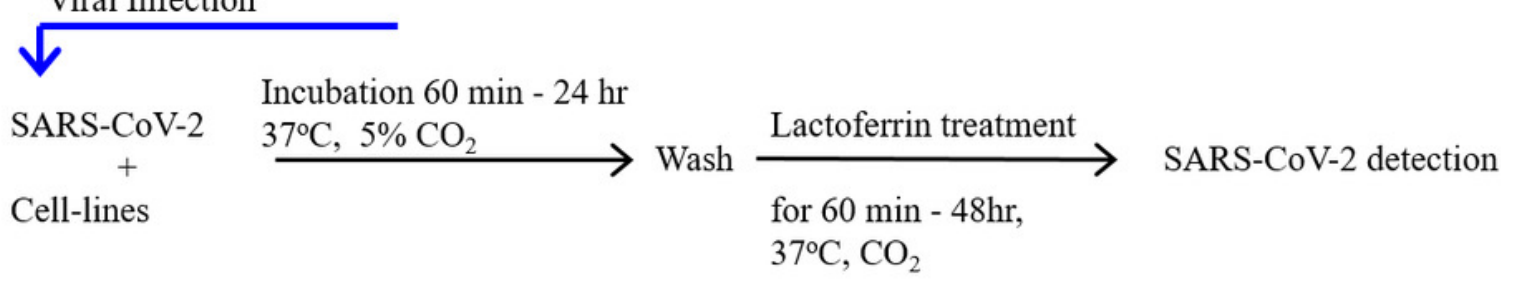




\section{Figure 2}

Figure 2. General scenario for generation and effects of small metabolites created as a result of the digestion of glycosylated lactoferrin and/or other whey milk glycoproteins by different microorganisms from the intestinal microbiota, on the COVID-1

Metabolites can be engaged in the direct interactions with the SARS-CoV-2 particles and/or show indirect potential against the viral replication through modulation of the immune response network via the antigen presenting cells (Dendritic cell and Toll-Like receptor 2, 4, and 8). These effects dependent on the kind of food stud and gut microbiota balance, and subsequently on their concentrations and distributions that change with the age. SCFAs (short-chain fatty acids), OSs (oligosaccharides), HMOs (human milk oligosaccharides).

\section{Lactoferrin and/or other whey milk glycoproteins}

Through numerous reaction cycles, thousands of metabolites are created
Enzymatic degradation and fermentation of carbohydrate and polysaccharides

HMOs

\section{Gut Microbiota}
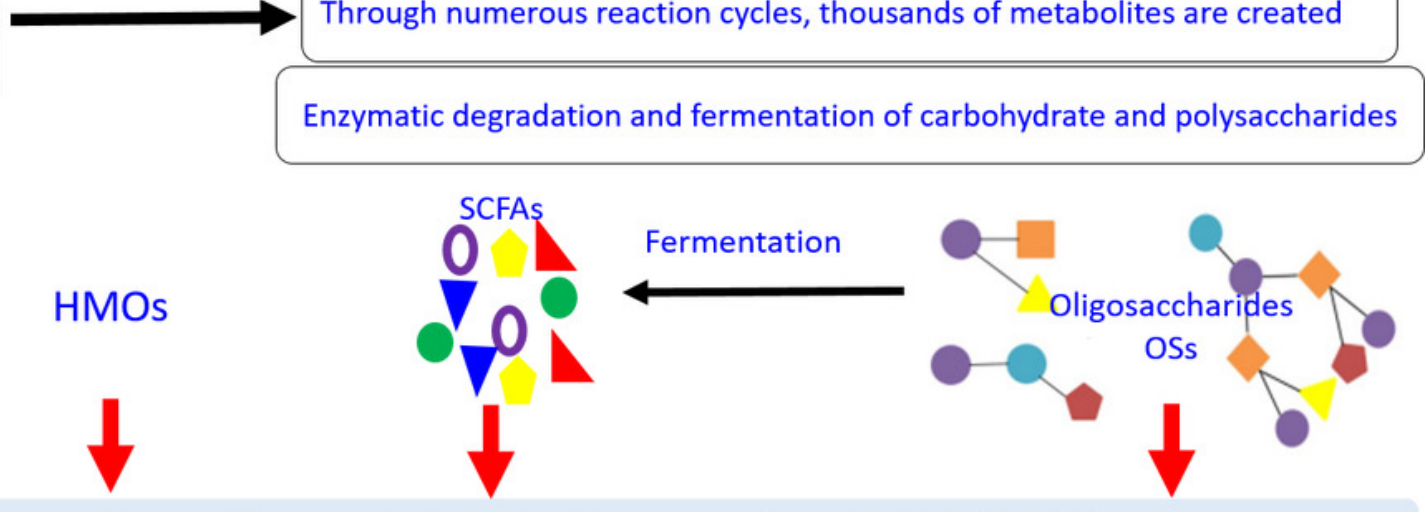

Systematic and/or peripheral effects against SARS-CoV-2

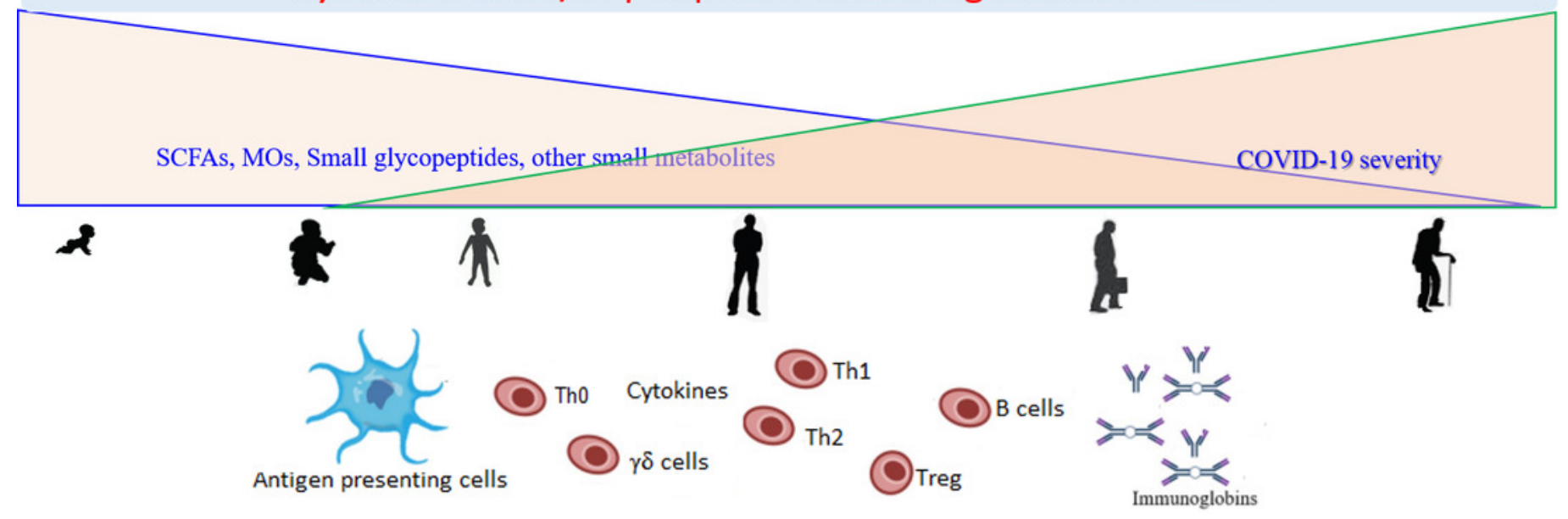




\section{Figure 3}

Figure 3. Schematic representation of how SARS-CoV-2 enters the target cells, where corresponding scenarios (S1-S3) are based on the in vitro studies and predication.

LF interacts with its corresponding host cell receptors through their glycan and/or via proteinprotein interactions (S1), LF interact with the viral spike protein to hide it from the ACE2 receptor (S2), and/or LF interacts with its corresponding receptors, and enter the target cells, which induce many intracellular cascades inhibiting viral replication (lactoferrin is shown by a green body).
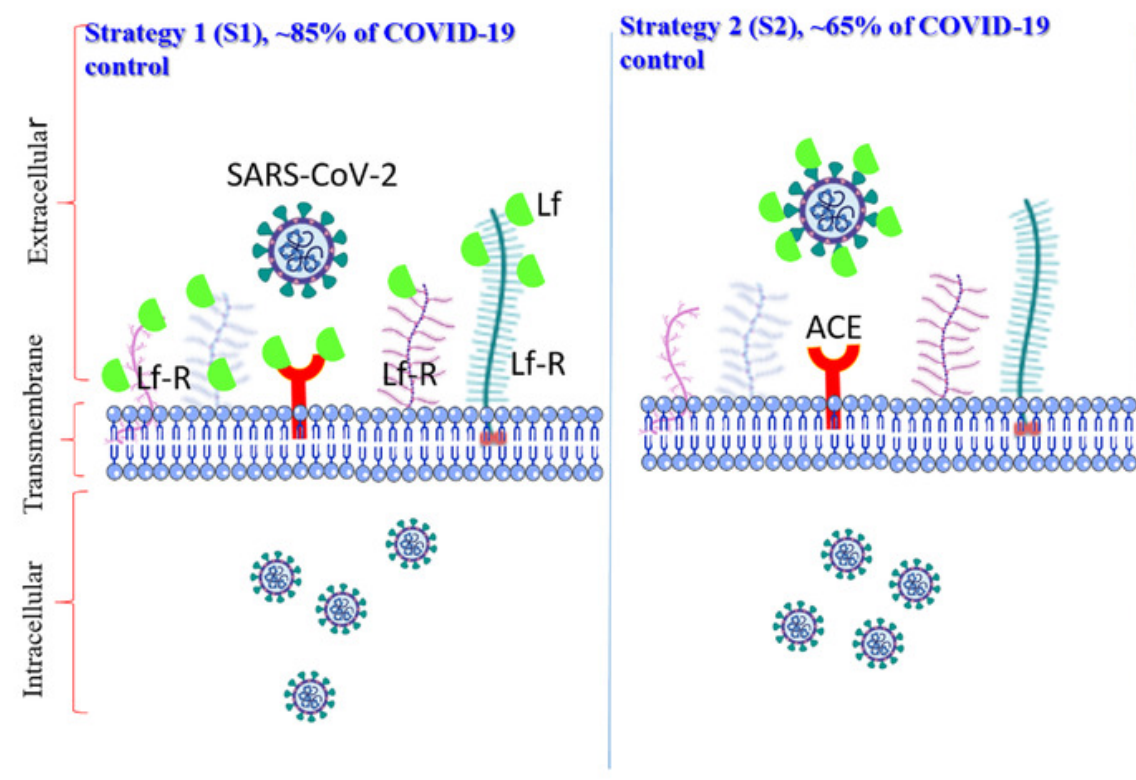

Strategy 3 (S3), $\sim 75 \%$ of COVID-19 control

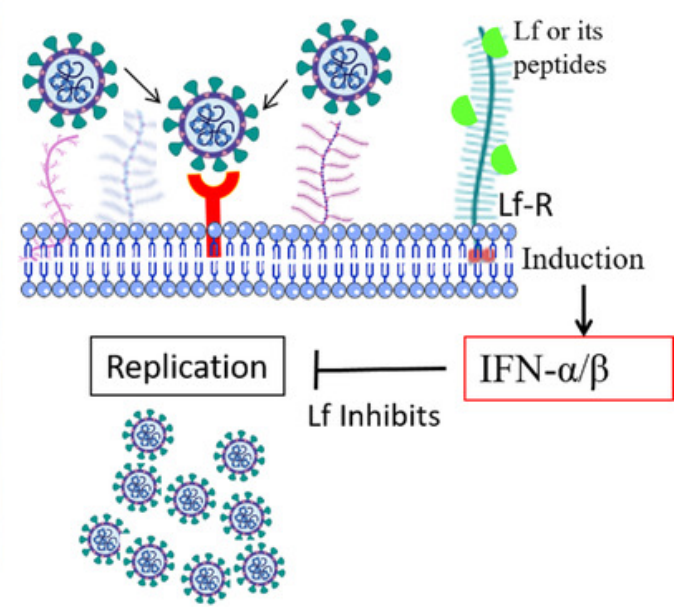

